\title{
Population model of an endangered amphibian: implications for conservation management
}

\author{
Samuel Pinya ${ }^{1, *}$, Giacomo Tavecchia $^{2}$, Valentín Pérez-Mellado ${ }^{3}$ \\ ${ }^{1}$ Interdisciplinary Ecology Group, Department of Biology, University of the Balearic Islands, Ctra. Valldemossa km 7.5, \\ 07122 Palma, Balearic Islands, Spain \\ ${ }^{2}$ Population Ecology Group, IMEDEA (CSIC-UIB), Carrer de Miquel Marquès 21, 07190 Esporles, Balearic Islands, Spain \\ ${ }^{3}$ Department of Animal Biology, Facultad de Biología, Campus Miguel de Unamuno s/n, University of Salamanca, \\ 37007 Salamanca, Spain
}

\begin{abstract}
Amphibian populations are declining worldwide, but for many taxa, robust estimates of demographic parameters to assess population state or trends are scarce or absent. We provide robust estimates of adult apparent survival of the endemic Mallorcan midwife toad Alytes muletensis using individual capture-recapture data collected over $4 \mathrm{yr}$ in a $60 \mathrm{~m}^{2}$ cistern. Moreover, we combined the vital rates into a stage-structured population model to estimate the expected longterm growth rate of the population. Apparent survival estimates of males and females were similar $(0.737 \pm 0.042$ and $0.726 \pm 0.045$, respectively) indicating that the egg-carrying behavior of males, typical of this species, does not reduce its survival probability. We found evidence of a low local survival of juveniles compared with adults, most likely due to permanent dispersal. Adult population size estimation provided higher tadpole:adult ratios than previously reported for this endangered species, suggesting an overestimation of the previous adult population size. Model projections suggested a stable population, since $\lambda$, the expected asymptotic growth rate of the population, was close to 1.00 .
\end{abstract}

KEY WORDS: Capture-recapture - Pollock's robust design - Population modeling $\cdot$ Alytes muletensis $\cdot$ Balearic Islands

\section{INTRODUCTION}

Approximately $32 \%$ of extant amphibian species are currently threatened, and $21 \%$ of these are on the brink of extinction (Stuart et al. 2008). A review of population trends in more than 900 amphibian populations of 157 species has revealed that amphibian declines are a worldwide phenomenon (Houlahan et al. 2000). Despite this high and ubiquitous extinction risk, there is a lack of demographic data on most species of concern. More than one-quarter of all amphibian species worldwide are in the Data Deficient category (Nori \& Loyola 2015), with insufficient information to enable an appropriate assessment of a species' risk of extinction. Therefore, there is an urgent need to obtain ecological parameters, such as

${ }^{*}$ Corresponding author: s.pinya@uib.es population size, population growth rate and adult survival probability, to enable an informed assessment of the current population state and to provide information for management actions (SalgueroGómez et al. 2016). Robust estimates of demographic parameters in natural populations can be obtained by capture, mark and recapture techniques (Burnham et al. 1987, Williams et al. 2002). However, these techniques are still scarcely considered in herpetological studies (Schmidt et al. 2002). Capture, mark and recapture techniques were only employed in $5 \%$ of the datasets reviewed in Houlahan et al. (2000) (Schmidt et al. 2002).

The Mallorcan midwife toad Alytes muletensis is an endemic and threatened species from the Balearic Islands (Spain). The introduction of alien invasive

(C) The authors 2017. Open Access under Creative Commons by Attribution Licence. Use, distribution and reproduction are unrestricted. Authors and original publication must be credited. 
species, such as Natrix maura and Batrachochytrium dendrobatidis, and the small number of populations led the species to the brink of extinction. Fortunately, conservation actions have mainly focused on protecting the remaining natural localities and re-introducing captive-reared animals in historical and new sites (Tonge \& Bloxman 1989, Román \& Mayol 1997). Previous assessments of the species' status only evaluated variables such as the occupancy area, the number of populations and the global tadpole population trend (Mayol et al. 2009). These assessments did not provide information on the breeding status of the population, a key issue for conservation management policies. Here we use capture, mark and recapture techniques to estimate apparent survival (hereafter, survival) and adult population size in a population without any known threats for the species. We incorporated these estimates together with fecundity measures into a matrix population model to estimate the expected long-term population growth rate (Caswell 2001). Thus, our objectives were (1) to estimate the population size from adult capture, mark and recapture data to compare with estimates based on the number of tadpoles observed, (2) to obtain a robust estimate of adult survival probabilities from individual encounter history data, (3) to provide a first population model for the species combining fertility measures, tadpole counts and survival probabilities and (4) to identify which component of the lifecycle is contributing the most to population growth.

\section{MATERIALS AND METHODS}

\section{Study site and data collection}

Data were collected from a population of toads living in a 19th century cistern of $60 \mathrm{~m}^{2}$, originally built to retain water for human and livestock consumption. The population was created during 1994-1996 from captive breeding individuals from population 8B (Escorca), by releasing 227 adults and 207 tadpoles, under the recovery plan for the species (Pinya 2009). The water level is not managed and depends on natural local rainfall. This population is particularly relevant because it lacks any known threats for the species, and is considered the population with the optimal body condition for the species (Pinya 2014). It constitutes close to $4 \%$ of the total number of tadpoles for this species. It is a well-established population, and larval counts, following the method proposed by Oliver et al. (2014), showed a general increase in the number of tadpoles from 1995 to 2011 (Fig. 1).
To obtain capture-recapture data, from 2008 to 2011 , the population was visited by 1 researcher for 3-4 nights per year between mid-July and early September to search for adults and metamorphosed juveniles. Toads were captured by hand inside crevices and/or holes and individually identified by their unique pattern of skin spots by photo-identification techniques. Captured toads were sexed and classified into adult and juveniles using morphometric characteristics (Pinya \& Pérez-Mellado 2009). For data analysis, individually recognized toads were arranged into 3 groups according to their sex-age at first capture, namely adult males, adult females and juveniles, i.e. individuals of unknown sex that had just completed metamorphosis.

\section{Adult survival}

Adult observations were coded into individual encounter histories, where ' 1 ' indicated a capture and ' 0 ' indicated a recapture failure at each recapture occasion. Then, annual survival probability, $S_{i}$, between sessions $i$ and $i+1$, and population size at $i, N_{i}$, were estimated by maximum likelihood procedure from incomplete encounter histories using Pollock's model (Pollock et al. 1990, Lebreton et al. 1992). Pollock's model estimates detection probability using the information collected during the short periods of time between the capture-mark-capture occasions within each year (named 'secondary occasions'), during which the population is assumed to be closed, i.e. animals do not leave or enter into the population. Annual survival is then estimated by pooling the observations collected during secondary occasions

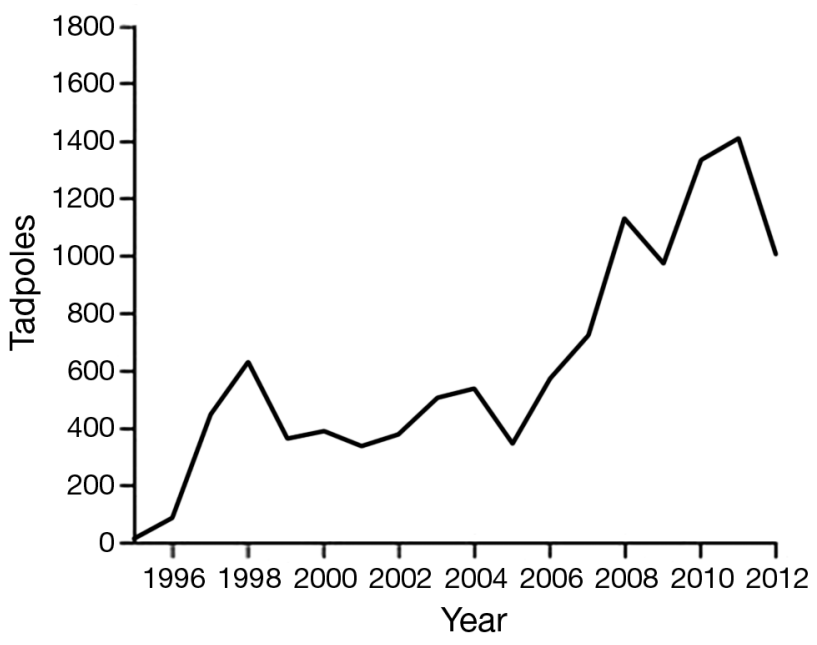

Fig. 1. Tadpole counts during the annual monitoring survey 
into annual 'primary' sessions, during which the population is open, i.e. animals can leave or enter into the population. For the analysis, we considered only adult data because of the small number of recaptures in primary sessions $(n=2)$ of toads first captured as juvenile. Capture-recapture models are based on several assumptions. The most important assumptions are that individuals must behave independently, that they share the same demographic parameters and that their future history should not be influenced by the present capture events. A comprehensive goodness of fit test for Pollock's robust design to test the validation of the assumption is not available. However, in open populations, the adequacy of a full time-dependent model was assessed by the informative tests (see Appendix I in Tavecchia et al. 2008) using the software U-CARE (Choquet et al. 2002). After assessing the goodness of fit of a general sexand time-dependent model on primary occasions only, we simplified the model structure by first assuming the same probability of capture for already and newly marked toads on secondary occasions. Following White \& Burnham (1999), we then identified a set of models according to the biological hypotheses of interest by modeling temporal movement, survival and capture probabilities as shown in Table 1. The difference between the models depends on the structure of the temporal movement probabilities (whether they are assumed to be constant, or time- or sexdependent), on the survival probability (whether it is assumed to be time- or sex-dependent) and the recapture probability (whether it is assumed to be timeor sex-dependent). All models were built and fit to the data using software MARK version 8.0 (White \& Burnham 1999). Model selection followed the corrected Akaike's information criterion $\left(\mathrm{AIC}_{\mathrm{c}}\right)$ value and the model with the lowest value was considered as the best compromise between model deviance and model complexity (Burnham \& Anderson 2002). The number of adults and the estimates used in the Lefkovitch model (see 'Lifecycle of midwife toads and average male fitness') were derived by averaging methods (Burnham \& Anderson 2002).

\section{Number of tadpoles, fertility and juvenile survival}

During the month of July, when the number of tadpoles is at its peak, we did an exhaustive count of tadpoles in the water mass. We used the standardized methods from the species' recovery plan to monitor the tadpole population (Oliver et al. 2014). This method consisted of counting all visible tadpoles inside the water mass with the help of an underwater torch. Most of these tadpoles conclude their metamorphosis by the end of the summer, but those from late clutches remain in the tadpole stage until the following spring. In 2011, we repeated the tadpole counts in January to estimate the number of tadpoles that remained in this state over their first winter. This

Table 1. Modeling temporal movement, survival and recapture probabilities of Mallorcan midwife toad Alytes muletensis. $\mathrm{AIC}_{\mathrm{c}}$ : corrected Akaike's information criterion; $\Delta \mathrm{AIC}_{\mathrm{c}}$ : difference in $\mathrm{AIC}_{\mathrm{c}}$ value from the model with the lowest $\mathrm{AIC} \mathrm{c}_{\mathrm{c}}$ AIC $\mathrm{Cw}_{\mathrm{cw}}$ : $\mathrm{AIC}_{\mathrm{C}}$ weight; $\mathrm{N}_{\mathrm{p}}$ : number of estimable parameters in the model. Yes/No represent whether time- or sex-dependent survival probabilities exist, or whether temporal movement probability is fixed or not. The retained model is in bold

\begin{tabular}{|c|c|c|c|c|c|c|c|c|c|c|c|}
\hline \multirow[t]{2}{*}{ Model } & \multicolumn{3}{|c|}{ Temporal movements } & \multicolumn{2}{|c|}{ Survival } & \multicolumn{2}{|c|}{$\longrightarrow$ Recapture -} & \multirow{2}{*}{$\mathrm{AIC}_{\mathrm{c}}$} & \multirow[t]{2}{*}{$\Delta \mathrm{AIC}_{\mathrm{c}}$} & \multirow{2}{*}{$\mathrm{AIC}_{\mathrm{cw}}$} & \multirow[t]{2}{*}{$\mathrm{N}_{\mathrm{p}}$} \\
\hline & Time & Sex & Fixed & Time & Sex & Time & Sex & & & & \\
\hline Model 1 & Yes & Yes & No & Yes & Yes & Yes & Yes & 230.5818 & 70.92 & 0 & 54 \\
\hline Model 2 & No & Yes & No & Yes & Yes & Yes & Yes & 210.1608 & 50.50 & 0 & 48 \\
\hline Model 3 & No & Yes & No & No & Yes & Yes & Yes & 202.1298 & 42.47 & 0 & 44 \\
\hline Model 4 & No & No & Random & No & Yes & Yes & Yes & 193.2338 & 33.57 & 0 & 41 \\
\hline Model 5 & No & Yes & Random & No & Yes & Yes & Yes & 196.0047 & 36.34 & 0 & 42 \\
\hline Model 6 & No & No & Yes & No & Yes & Yes & Yes & 190.1087 & 30.45 & 0 & 40 \\
\hline Model 7 & No & Males & No & No & Yes & Yes & Yes & 196.4962 & 36.84 & 0 & 42 \\
\hline Model 8 & No & Females & No & No & Yes & Yes & Yes & 195.5732 & 35.91 & 0 & 42 \\
\hline Model 9 & No & No & Yes & No & Yes & Primary only & Yes & 182.2255 & 22.56 & 0 & 14 \\
\hline Model 10 & No & No & Yes & No & Yes & Yes & Additive & 165.224 & 5.56 & 0.04 & 29 \\
\hline Model 11 & No & No & Yes & Females only & Yes & Yes & No & 167.2736 & 7.61 & 0.01 & 27 \\
\hline Model 12 & No & No & Yes & $\begin{array}{l}\text { Linear trend } \\
\text { in females }\end{array}$ & Yes & Yes & No & 164.5893 & 4.93 & 0.06 & 26 \\
\hline Model 13 & No & No & Yes & No & Yes & Yes & No & 162.1655 & 2.50 & 0.2 & 25 \\
\hline Model 14 & No & No & Yes & No & Yes & No & Yes & 184.1509 & 24.49 & 0 & 18 \\
\hline Model 15 & No & No & Yes & No & No & Yes & No & 159.6599 & 0 & 0.69 & 24 \\
\hline Model 16 & No & No & Yes & No & No & No & No & 180.0302 & 20.37 & 0.0 & 13 \\
\hline
\end{tabular}


information was used to calculate the proportion of tadpoles that completed metamorphosis before the winter.

Individual fertility and juvenile survival in amphibians are challenging measures to obtain in natural populations. This is particularly evident in midwife toads, where clutches are carried by males. The number of clutches observed depends on the probability of capturing a breeding male, i.e. the clutches carried by males that escaped capture are unknown. We counted the number of eggs of all clutches observed on males. The average number of fertile eggs, i.e. those eggs which contained developing tadpoles, was then calculated by dividing the total of number of fertile eggs by the total number of eggs in each clutch. Males can carry 1 to 3 clutches at the same time and when the number of eggs carried is more than 14 , it is assumed that they came from more than one clutch (Bush 1993, Pinya \& Pérez-Mellado 2014). We relied on an equally simple estimate for the survival of tadpoles and juveniles, denoted $S^{\mathrm{T}}$ and $S^{\mathrm{J}}$, respectively. These quantities are proportions that were estimated by dividing the number of animals observed in a given state by the number observed in the successive one, similar to the approach used for life tables. Because we have assumed each individual to be independent, the variance of the proportion, $\theta$, can be calculated as $(1-\theta) \theta / k$, where $k$ is the sample size.

\section{Lifecycle of midwife toads and average male fitness}

The lifecycle of Mallorcan midwife toads can be simplified into 3 main stages: tadpole, juvenile and adult. The breeding season lasts approximately 6 mo, with the first clutches laid at the beginning of March and the last clutches as late as August (Román \& Mayol 1997); at some localities, the breeding season even lasts until autumn. Animals born early begin

Table 2. Available information at individual and population level for the Mallorcan midwife toad Alytes muletensis. CR: capture-recapture

\begin{tabular}{|lcccc|}
\hline Year & $\begin{array}{c}\text { No. of CR- } \\
\text { occasions }\end{array}$ & $\begin{array}{c}\text { No. of } \\
\text { captured adults }\end{array}$ & $\begin{array}{c}\text { No. of } \\
\text { juveniles }\end{array}$ & $\begin{array}{c}\text { No. of } \\
\text { tadpoles }\end{array}$ \\
\hline 2008 & 3 & 50 & 2 & 1137 \\
2009 & 4 & 31 & 0 & 971 \\
2010 & 5 & 51 & 9 & 1333 \\
2011 & 3 & 35 & 4 & 1414 \\
& 15 & 167 & 15 & $401^{\mathrm{a}}$ \\
Total & 15 & & & \\
a Winter survey & & & \\
\hline
\end{tabular}

metamorphosis in July. For these individuals, the transition to the juvenile stage typically takes place during the first summer. However, tadpoles from late clutches become juvenile the next summer, spending winter in the tadpole stage. The juvenile stage lasts approximately $1 \mathrm{yr}$ in males and $2 \mathrm{yr}$ in most females (Pinya \& Pérez-Mellado 2013). Thus, individuals from early clutches are sexually mature at $1 \mathrm{yr}$, while adults from late clutches will mature a year later. Free-living females typically produce 2 clutches per year (Alcover et al. 1984), with an average of 12 eggs (Pinya \& Pérez-Mellado 2014). Males can carry a maximum of 3 clutches at once. We assumed that males fertilized only the eggs that they carry and combined the stage-dependent survival and fecundity values into a Lefkovitch matrix model, $\mathbf{M}$ (Caswell 2000). The matrix $\mathbf{M}$ contains the parameters that describe the transitions between the stages from time $t$ to $t+1$ as:

$$
\mathbf{M}=\left[\begin{array}{lllllll}
0 & 0 & F S^{\mathrm{M}} & ; \\
(1-Z) S^{\mathrm{T}} & 0 & 0 ; Z S^{\mathrm{T}^{*}} & S^{\mathrm{J}} & S^{\mathrm{M}}
\end{array}\right]
$$

where $Z$ is the probability of becoming a juvenile during the first summer, $S^{\mathrm{M}}$ is the annual survival for males, $S^{\mathrm{J}}$ is the annual survival of juvenile toads, $S^{\mathrm{T}}$ is the annual survival of a tadpole, $F$ is the number of fertile eggs per breeding males divided by 2 (assuming a 1:1 sex ratio) and $S^{\mathrm{T}^{*}}$ is the annual survival probability of a tadpole that became a juvenile in the first summer. This last parameter is the combined probability of surviving 4 mo as a tadpole, i.e. $\left(S^{\mathrm{T}}\right)^{4 / 12}$, and $8 \mathrm{mo}$ as a juvenile, i.e. $\left(S^{\mathrm{J}}\right)^{8 / 12}$. We assumed an even sex ratio and 3 clutches per breeding male and per season. The greatest eigenvalue of $\mathbf{M}$, noted $\lambda$, is the expected asymptotic growth rate of the population. It can also be viewed as the average individual fitness within the population (see Roff 1992, Caswell 2000, van Tienderen 2000). To account for parameter uncertainty, for each parameter in the matrix, we randomly selected a value from a distribution with the estimated mean and variance (Table 2). We replicated this procedure 1000 times to estimate $\lambda$ and its standard error. Finally, we used the average values of the parameters to calculate the elasticity of each matrix entry, that is, to find the proportional contribution of a given parameter to $\lambda$.

\section{RESULTS}

\section{Adult survival and population size}

A total of 201 toads were captured during the period 2008-2011: 64 adult males, 55 adult females 
and 15 juveniles. Approximately $42 \%$ of these animals were recaptured at least once over the study period (39\% for those used in the survival analysis, see below).

The model with time- and sex-dependent parameters (Model 1) did not adequately explain our data $\left(\chi^{2}{ }_{7}=4.91, \mathrm{p}=0.67\right)$. We reduced the number of parameters describing temporal movements, but the AICc values indicated that data were not consistent with temporal movements into and out of the study area (Model 6; Table 1). Similarly, we found no evidence of a sex-dependent probability of recapture (Models 6, 10 and 13; Table 1) but we did retain a variation of it over time (Model 14; Table 1). Finally, Model 13 suggested a slightly higher survival for males than for females, but this difference was not retained (Model 15; Table 1). The model with the lowest AICc value was Model 15, consisting of a fixed temporal movement probability, no time- or sex-dependent survival probabilities and no timedependent recapture probabilities. The model indicated an annual local survival of 0.728 (95\% confidence limits: 0.627-0.809), which suggested a lifetime expectancy of about $3 \mathrm{yr}$ after adulthood. Average $( \pm$ SD) survival estimates showed similar values for males and females, which were $0.737 \pm 0.042$ and $0.726 \pm 0.045$, respectively. Average estimates of derived parameters indicated that the adult population size increased in the first year from 102 toads (49 \pm 5 males and $53 \pm 16$ females) to $127(54 \pm 10$ males and $73 \pm 19$ females), but decreased to 85 in

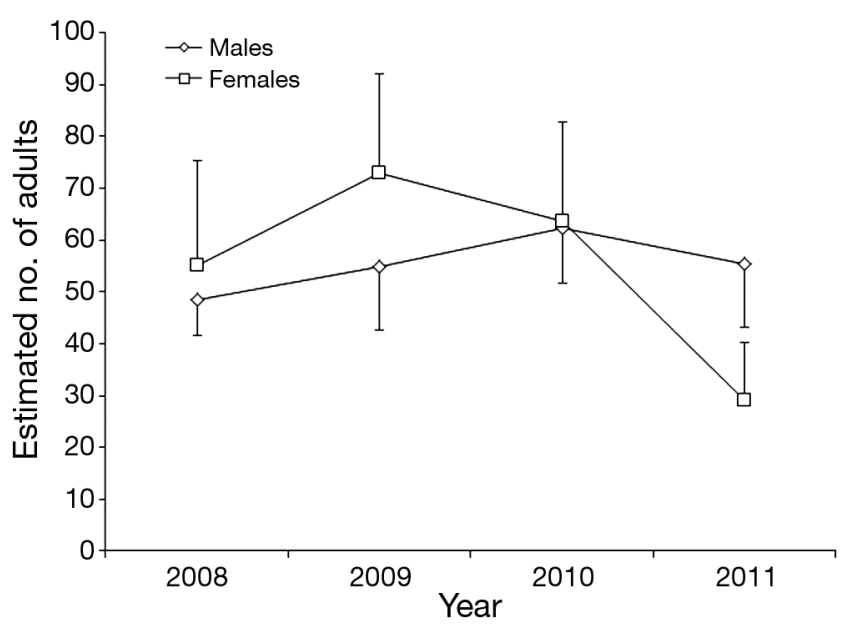

Fig. 2. Averaged estimates of summer adult population size of Mallorcan midwife toads Alytes muletensis as derived parameters from Pollock's robust design models in Table 1. Bars indicate $95 \%$ CI from the unconditional standard error (only upper and lower intervals are plotted for females and males, respectively)
2011 (56 \pm 12 males and $29 \pm 11$ females). The geometric mean of the 3 population growth rates was 0.934 . The observed dynamics were due mainly to the fluctuations in female numbers (Fig. 2). The decrease in female numbers was not mirrored by a similar trend in the survival probability (Models 11 and 12; Table 1). The yearly estimates of total adult population sizes were about 3 times the observed number of adult toads each year. Indeed, the average probability of recapture per occasion was $0.112 \pm$ 0.007 , which indicated an average p-value of $1-$ $\left(1-0.11^{15 / 4}\right)=0.36$ per session. Tadpole:adult ratios showed values of $11.92 \pm 3.61$ tadpoles per adult.

\section{Midwife toad lifecycle, fertility and juvenile survival}

We counted an average of $1213.75 \pm 199.28$ tadpoles in the pond each summer $(2008=1137,2009=$ $971,2010=1333$ and $2011=1414)$. Out of the 1333 tadpoles found in summer 2010, 401 (30\%) were still present in January 2011. During the study period, we found 5 males carrying eggs. In this population, the average number of fertile eggs carried by a male was $15 \pm 5$.29. From 2009 to 2011, we observed an average of 4.3 juveniles per summer. Assuming that a juvenile had the same detection probability as an adult toad (0.36), we estimate that 12 juveniles were present in the pond each summer $(4.3 / 0.36)$. This leads to an average value for the local survival of tadpoles of $0.01(=12 / 1213.75$; Table 1$)$. Similarly, the survival of juvenile toads was 0.18 , calculated as the number of juveniles that were seen to reach adulthood during our study period (2 out of 11).

\section{Midwife toad lifecycle and average male fitness}

The deterministic Lefkovitch model containing the average values of stage-dependent survival and fertility (Fig. 3) suggested an asymptotic growth rate of 1.005. The value from the stochastic matrices was similar (0.99) with a 95\% CI of 0.818-1.179. Elasticity measures indicated that the population growth rate was influenced mainly by adult survival, with an elasticity value of 0.79 (Fig. 4). The next most influential parameters were fertility and the probability of leaving the tadpole state in the first summer, with elasticity values of 0.21 and 0.20 , respectively. The elasticity of juvenile survival was 0.084 . A population in which all animals complete the metamorphosis before the summer $(Z=1)$ would result in $31 \%$ higher population growth. 


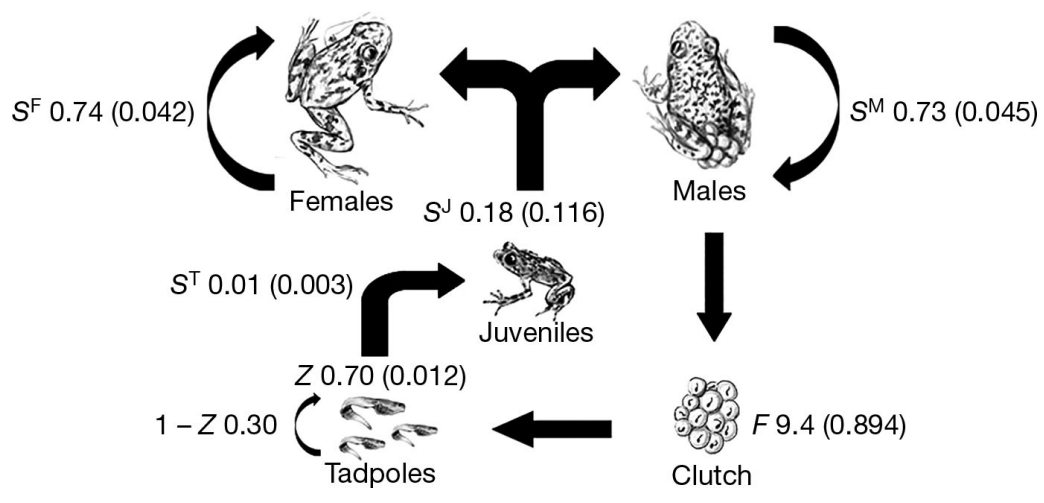

Fig. 3. Lifecycle of a male Mallorcan midwife toad Alytes muletensis. F: average number of tadpoles per females; $Z$ : proportion of tadpoles that complete the metamorphosis during the first year; $1-Z$ : proportion of tadpoles that overwinter; $S^{\mathrm{T}}$ : survival from tadpole to juvenile; $S^{\mathrm{J}}$ : survival from juvenile to adult; $S^{\mathrm{F}}$ : female survival; $S^{\mathrm{M}}$ : male survival. Values in parentheses show SD

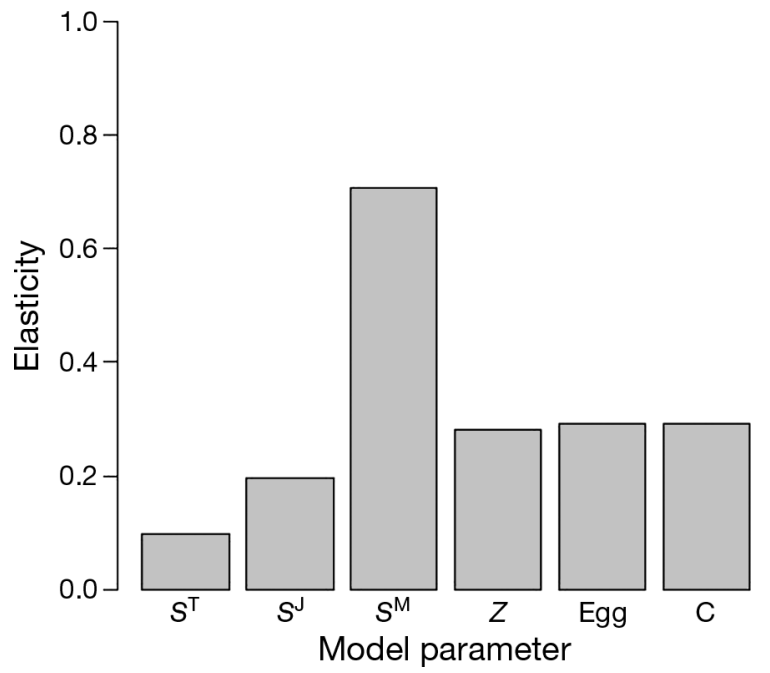

Fig. 4. Elasticity values of lower-level parameters of male midwife toads' lifecycle. $S^{\mathrm{J}}$ : survival from juvenile to adult; C: proportion of fertile eggs per clutch. For other abbreviations see Fig. 3

\section{DISCUSSION}

Even though we expect a low survival rate of the endangered Alytes muletensis, in this study, the annual survival of the Mallorcan midwife toad was similar to the survival estimated for other common anuran species (Wells 2007 and references therein), such as the survival of the pool frog Rana lessonae (survival ranging from 0.72 to 0.84 , Holenweg Peter, 2001) and the survival estimated for the common toad Bufo bufo (0.77, Heusser 1968). In anuran species, Monnet \& Cherry (2002) found that the sexual dimorphism in body size indicated different survival rates in males and females. A difference between male and female survival was found in species of the genus Desmognathus (Tilley 1980), in the Columbian spotted frog Rana luteiventris (Turner 1960) and the common frog Rana temporaria (Gibbons \& McCarthy 1984). However, our results based on local survival indicated that the average lifespan was similar for both sexes, confirming previous results from Pinya \& Pérez-Mellado (2013). This suggests that the reproductive investment of adult males carrying clutches does not result in lower probabilities of local survival than survival probabilities of females. We found evidence for low juvenile local survival compared with adult values. This difference could be due to permanent dispersal, as capture, mark and recapture models do not distinguish permanent movements from mortality. Juvenile survival was estimated by correcting the observations by the same probability of detection as adults (0.36). Data were too sparse to apply capture-recapture models to animals of this age class because only 2 toads marked as juveniles have been seen in subsequent years (primary occasions). However, 6 out of 13 were recaptured the same year of marking, i.e during secondary occasions, which would suggest a detection probability of $0.46(6 / 13)$, supporting the assumption of a similar detection probability as for adults. A change in juvenile detection probability will be reflected directly in the estimate of their survival and, in turn, in the population growth rate of the population. For example, a detection probability of 0.13 (half the probability of adults) would lead to a juvenile survival of 0.363 and an increase in population growth rate of $\sim 10 \%$. We have no reason to think that juveniles had a lower detection probability as they used the same crevice or resting areas as adults, and toads were caught independently of their age. Even so, juvenile survival would still be much lower than adult survival. This could be due to permanent dispersal, as capture, mark and recapture models do not distinguish permanent movements from mortality.

The stage-dependent matrix describing the male midwife toad lifecycle suggested a constant population $(\lambda \approx 1.00)$. This result must be treated with caution because the model is an extreme simplification of the midwife toad lifecycle. For example, a continuous rather than a discrete model would probably have been more appropriate. However, available data were not sufficiently frequent to apply continuous 
models of survival and fertility. Also, juvenile and tadpole survivals were recapture-conditioned estimates and were probably underestimated (Schmidt 2003). Nevertheless, the elasticity values of each parameter are likely to be less biased because they were calculated as proportional changes (Caswell 2001). The parameter with the highest elasticity was adult survival, suggesting that a small increase in adult mortality would have a large effect on the population growth rate. This result explains the rapid extinction of several midwife toad populations due to the introduction of non-native predators. Interestingly, our model suggested an important role for the probability of undergoing an early metamorphosis. This is because toads which hatched early began to breed 1 yr earlier than those which hatched late. From a conservation point of view, this result suggests that environmental conditions have an important role as potential drivers of the optimal conditions for early metamorphosis. Although this was not the parameter with the highest elasticity, selection for a fast cycle might play an important role in sexual-size dimorphism. For example, in birds of prey, which show female-biased sexual-size dimorphism, earlyhatched birds are mainly males. This skewed sexratio is thought to be adaptive as early-born males can breed after the first year of age (Griggio et al. 2002). Nevertheless, given the cost of a late metamorphosis, it is striking that $30 \%$ of tadpoles are still juveniles after a year. A possible explanation is that the variability of environmental conditions maintains late-metamorphic tadpoles as insurance for reproductive success, as postulated for other taxa (Mock \& Forbes 1995). Studies of amphibians' lifecycle in temperate regions should investigate the link between winter temperatures and the probability of an early metamorphosis, as this might directly influence population dynamics.

Population size estimation based on capture, mark and population techniques provided a $32 \%$ higher tadpole:adult ratio compared with the previously accepted ratios. For instance, Alcover et al. (1984) proposed a tadpole:adult ratio based on the assumption that females produce 9 eggs, twice a year, resulting in a tadpole:adult ratio of 9:1. Under this ratio, the adult population size was estimated as 1000-3000 adults (Gasc et al. 1997, Arnold 2003). Our results show an increase in the ratio, suggesting that an overestimation of the adult population may have occurred over the years.

This first population model of $A$. muletensis developed here provides an important tool for comparative studies. A population with a similar fertility but a lower adult survival than the one found here is likely to go extinct. Current population monitoring based on tadpole counts is useful to show tendencies over time (Oliver et al. 2014) but it does not provide enough demographic information for decision-making. Besides, it does not seem to be sufficient to understand the spatiotemporal variations of populations. Thus, tadpole population monitoring should be complemented with adult monitoring. Furthermore, new studies should focus on other populations to estimate population size, to obtain more accurate tadpole: adult ratios, to assess survival probability patterns and to build up new and more complete lifecycles. Altogether, this would provide a more useful adultbased management tool.

Acknowledgements. The manuscript is part of S.P.'s PhD thesis at the University of the Balearic Islands. The study was partially funded by the Agreement between the University of the Balearic Islands and Ferrer Hotels to develop ecological studies for Mallorcan midwife toad preservation. We thank J. A. Oliver, M. A. Vanrell and J. C. Salom of the Government of the Balearic Islands, who gave us administrative support and provided the capture permits for our study. We are also grateful to all the people who provided support during the fieldwork, especially X. Manzano, J. Bonnin and THE Balearik Association. X. Canyelles did the illustration of Mallorcan midwife toads in Fig. 3.

\section{LITERATURE CITED}

Alcover JA, Mayol J, Jaume D, Alomar G, Jurado J (1984) Biologia i ecologia de les poblacions relictes de Baleaphryne muletensis a la muntanya mallorquina. In: Alcover JA, Hemmer $\mathrm{H}$ (eds) Història biològica del ferreret. Monografíes Científiques, 3. Editorial Moll, Palma de Mallorca, p 129-152

Arnold EN (2003) Reptiles and amphibians of Europe. Princeton University Press, Princeton, NJ

Burnham KP, Anderson DR (2002) Model selection and multimodel inference: a practical information-theoretic approach. Springer-Verlag, New York, NY

Burnham KP, Anderson DR, White GC, Brownie C, Pollock KH (1987) Design and analysis methods for fish survival experiments based on release recapture. Monograph 5. American Fisheries Society, Bethesda, MD

Bush S (1993) Courtship and male parental care in the Majorcan midwife toad, Alytes muletensis. PhD dissertation, University of East Anglia, Norwich

* Caswell H (2000) Prospective and retrospective perturbation analyses: their roles in conservation biology. Ecology 81: 619-627

Caswell H (2001) Matrix population models, 2nd edn. Sinauer Press, Sunderland, MA

Choquet R, Reboulet AM, Lebreton JD, Gimenez O, Pradel R (2002) U-CARE 2.2: user's manual. CEFE-CNRS. https:// www.cefe.cnrs.fr/fr/actus/livres/34-french/recherche/bc/ bbp/264-logiciels

Gasc JP, Cabela A, Crnobrnja-Isailovic D, Dolmen K and others (1997) Atlas of amphibians and reptiles in Europe. 
Societas Europaea Herpetologica and Muséum National d'Histoire Naturelle, Paris

Gibbons MM, McCarthy TK (1984) Growth, maturation and survival of frogs Rana temporaria L. Ecography 7:419-427

Griggio M, Hamerstrom F, Rosenfield RN, Tavecchia G (2002) Seasonal variation on the sex ratios of fledgling American kestrel: a 30 year study. Wilson Bull 114:474-478

Heusser H (1968) Die Lebensweise der Erdkröte, Bufo bufo (L.): Wanderungen und Sommerquartiere. Rev Suisse Zool 75:927-982

Holenweg Peter AK (2001) Survival in adults of water frog Rana lessonae and its hybridogenetic associate Rana esculenta. Can J Zool 79:652-661

*Houlahan JE, Findlay CS, Schmidt BR, Myer AH, Kuzmin SL (2000) Quantitative evidence for global amphibian population declines. Nature 404:752-755

* Lebreton JD, Burhnam KP, Clobert J, Anderson DR (1992) Modelling survival and testing biological hypotheses using marked animals: a unified approach with case studies. Ecol Monogr 62:67-118

Mayol J, Griffiths R, Bosch J, Beebee T and others (2009) Alytes muletensis. The IUCN Red List of Threatened Species. e.T977A13099129. http://dx.doi.org/10.2305/ IUCN.UK.2009.RLTS.T977A13099129.en (accessed 21 June 2016)

Mock DW, Forbes LS (1995) The evolution of parental optimism. Trends Ecol Evol 10:130-134

Konnet JM, Cherry MI (2002) Sexual size dimorphism in anurans. Proc R Soc B 269:2301-2307

Nori J, Loyola R (2015) On the worrying fate of data deficient amphibians. PLOS ONE 10:e0125055

Oliver JA, Manzano X, Pinya S (2014) Contando ferrerets. Veinticinco años de recuentos visuales de una especie en peligro de extinción. Bol Asoc Herpetol Esp 25:37-43

Pinya S (2009) Demografía de la població de ferrerets (Alytes muletensis, Sanchíz \& Adrover, 1977) de la localitat dels Aljubets (Banyalbufar). In: Pinya S, Vanrell MA (eds) I Jornades de Biodiversitat Del Paratge Natural de La Serra de Tramuntana. Ponències I Resums. Espais de Natura Balear. Conselleria de Medi Ambient, Palma, p 49-50

Pinya S (2014) Biología y conservación del ferreret, Alytes muletensis. PhD thesis, University of the Balearic Islands, Palma

Pinya S, Pérez-Mellado V (2009) Individual identification and sexual dimorphism in the endangered balearic midwife toad, Alytes muletensis (Sanchíz and Adrover, 1981). Amphib-Reptil 30:439-443

Pinya S, Pérez-Mellado V (2013) Ageing and growth of the

Editorial responsibility: Michael Mahony,

Callaghan, New South Wales, Australia endangered midwife toad Alytes muletensis. Endang Species Res 22:263-268

Pinya S, Pérez-Mellado V (2014) Clutch size in wild populations of Alytes muletensis. Acta Herpetol 9:115-117

Pollock KH, Nichols JD, Brownie C, Hines JE (1990) Statistical inference for capture-recapture experiments. Wildl Monogr 107:1-97

Roff DA (1992) The evolution of life histories. Theory and analysis. Chapman \& Hall, New York, NY

Román A, Mayol J (1997) La recuperació del ferreret. Documents tècnics de conservació 1 . Conselleria de Medi Ambient, Ordenació del Territori i Litoral, Palma de Mallorca

Salguero-Gómez R, Jones OR, Archer CR, Bein C and others (2016) COMADRE: a global data base of animal demography. J Anim Ecol 85:371-384

Schmidt BR (2003) Count data, detection probabilities, and the demography, dynamics, distribution, and decline of amphibians. C R Biol 326(Suppl 1):119-124

Schmidt BR, Schaub M, Anholt BR (2002) Why you should use capture-recapture methods when estimating survival and breeding probabilities: on bias, temporary emigration, over dimension, and common Toads. AmphibReptil 23:375-388

Stuart SN, Hoffman M, Chason J, Cox N, Berridge R, Ramani P, Young B (2008) Threatened amphibians of the world. IUCN, Gland and Lynx Edicions, Barcelona

* Tavecchia G, Minguez E, de Leon A, Louzao M, Oro D (2008) Living close, doing differently: small-scale asynchrony in demographic parameters in two species of seabirds. Ecology 89:77-85

Tilley SG (1980) Life histories and comparative demography of two samalander populations. Copeia 1980:806-821

* Tonge SJ, Bloxman Q (1989) Breeding the Mallorcan midwife toad Alytes muletensis in captivity. Int Zoo Yearb 28:45-53

Turner FB (1960) Population structure and dynamics of the western spotted frog, Rana p.pretiosa Baird \& Ginard in Yellowstone Park, Wyoming. Ecol Monogr 30:251-278

*van Tienderen PH (2000) Elasticities and the link between demographic and evolutionary dynamics. Ecology 81: 666-679

Wells KD (2007) The ecology and behaviour of amphibians. The University of Chicago Press, Chicago, IL

White GC, Burnham KP (1999) Program MARK: survival estimation from populations of marked animals. Bird Study 46 (Suppl 1):S120-S138

Williams BK, Nichols JD, Conroy MJ (2002) Analysis and management of animal populations. Academic Press, San Diego, CA

Submitted: June 24, 2016; Accepted: April 23, 2017

Proofs received from author(s): June 12, 2017 